\title{
Studies of the Deepwater Horizon Oil Spill With the UAVSAR Radar
}

\author{
Cathleen E. Jones, ${ }^{1}$ Brent Minchew, ${ }^{2}$ Benjamin Holt, ${ }^{1}$ and Scott Hensley ${ }^{1}$
}

On 22-23 June 2010, the Uninhabited Aerial Vehicle Synthetic Aperture Radar (UAVSAR) L band radar imaged the Deepwater Horizon oil spill and the effects of oil that was transported within the Gulf of Mexico. We describe the campaign and discuss the unique contributions of the UAVSAR radar to the study of the detection, migration, and impact of oil from the spill. We present an overview of UAVSAR data analyses that support the original science goals of the campaign, namely, (1) algorithm development for oil slick detection and characterization, (2) mapping of oil intrusion into coastal wetlands and intercoastal waterways, and (3) ecosystem impact studies. Our study area focuses on oil-affected wetlands in Barataria Bay, Louisiana. The results indicate that fine resolution, low-noise, L band radar can detect surface oil-on-water with sufficient sensitivity to identify regions in a slick with different types of oil/emulsions and/or oil coverage; identify oil on waters in inland bays and differentiate mixed/weathered oil from fresh oil as it moves into the area; identify areas of potentially impacted wetlands and vegetation in the marshes; and support the crisis response through location of compromised booms and heavily oiled beaches.

\section{THE UAVSAR CAMPAIGN TO STUDY THE DEEPWATER HORIZON (DWH) OIL SPILL}

During the DWH oil spill, NASA supported a deployment of the Uninhabited Aerial Vehicle Synthetic Aperture Radar (UAVSAR) platform for scientific studies of the oil spill and its impact. The UAVSAR Gulf Oil Spill Campaign was initiated with three science goals:

1. Develop and validate algorithms for improved discrimination of oil slicks on water using $\mathrm{L}$ band radar, including studies of the use of low-noise active radar instruments to determine oil properties from backscatter returns.

\footnotetext{
${ }^{1}$ Jet Propulsion Laboratory, California Institute of Technology, Pasadena, California, USA.

${ }^{2}$ Seismological Laboratory, California Institute of Technology, Pasadena, California, USA.

Monitoring and Modeling the Deepwater Horizon Oil Spill: A Record-Breaking Enterprise Geophysical Monograph Series 195

Copyright 2011 by the American Geophysical Union. 10.1029/2011GM001113
}

2. Study the use of radar for determining the extent of oil penetration into sensitive coastal ecological zones, in particular, mapping the spread of oil from the Gulf of Mexico (GOM) into coastal wetlands.

3. Study the use of radar for identifying vegetation that has been affected by oil, determining the extent and nature of the damage, and tracking ecosystem recovery.

The first two objectives had short-term observation requirements commensurate with the time during which the oil slick was present on the ocean waters and the times when oil from the spill intruded into coastal ecological zones. The third objective requires a sustained observation plan spanning multiple years, but over a smaller area than the first deployment, basically covering only ecologically sensitive areas directly impacted by the spill. The first two goals help to enable the third because assessing the long-term ecosystem impact of the DWH spill necessarily requires knowledge of where the oil was actually dispersed within the wetlands. Visual observations of the wetlands mainly provide information about canopy impact, but $\mathrm{L}$ band synthetic aperture radar (SAR) offers the potential of detecting oil below the canopy, providing more complete information about the oil extent in vegetated areas where ecosystem recovery should be monitored. 
UAVSAR was deployed in the GOM region on 22-23 June 2010, where we collected fine-resolution, fully polarimetric, L band SAR data imaging $\sim 120,000 \mathrm{~km}^{2}$ of surface area (Figure 1). Data over open water were collected extending from south of the DWH rig site northward to the Louisiana coast, southeast of the rig site along Eddy Franklin present at the time in the upper GOM [Liu et al., this volume], and further south off the western Florida coast, within the GOM Loop Current system [Liu et al., this volume]. Land and coastal waters along nearly the entire U.S. Gulf coast were imaged, including extensive inland coverage of southern Louisiana wetlands. The 23 June flight was timed to collect data over the eastern Louisiana marshes near low tide to observe the extent of oil-affected vegetation.

Our analyses of the UAVSAR data set collected in June 2010 focuses on oil in the open water of the Gulf near the DWH rig site and within coastal marshes of southern Louisiana that had experienced spatially extensive shoreline oil impacts prior to the UAVSAR collections and in which oil from the DWH spill was known to be present at the time of the UAVSAR overflight. The open ocean oil discrimination results presented here builds on previous work prepared for publication by the authors (B. Minchew, C. Jones, and B. Holt, Polarimetric analysis of backscatter from the Deepwater Horizon oil spill using 1-band radar, submitted to IEEE
Transactions on Geoscience and Remote Sensing, 2011), referred to herein as our previous analysis.

As validation data, we use ground observations in Barataria Bay, Louisiana, collected on 23 June 2010 in support of the UAVSAR flights (Bruce A. Davis, private communication, 2010), photos and visual observations from NOAA and Environmental Protection Agency (EPA) overflights of the spill, NOAA oil trajectory and Shoreline Cleanup Assessment Technique maps, and optical imagery from the Galileo Group, Inc. Parts of the Barataria Bay study area were imaged by multiple UAVSAR flight lines on 22-23 June 2010, providing corroborating evidence of oil from different observation directions. One of the flight lines was a repeat of a line collected almost exactly a year earlier on 17 June 2009. This data set provides a baseline for characteristic radar returns from the shallow water areas and vegetation in the restricted bay and estuaries in the absence of the DWH oil, which are expected to be subject to significant seasonal-dependent suspended sediment loads.

In the following sections, we briefly describe the UAVSAR instrument, discuss oil detection and differentiation in open water, oil-impact extent mapping in coastal wetlands, and potential uses of high-resolution $\mathrm{L}$ band radar during crisis response operations.

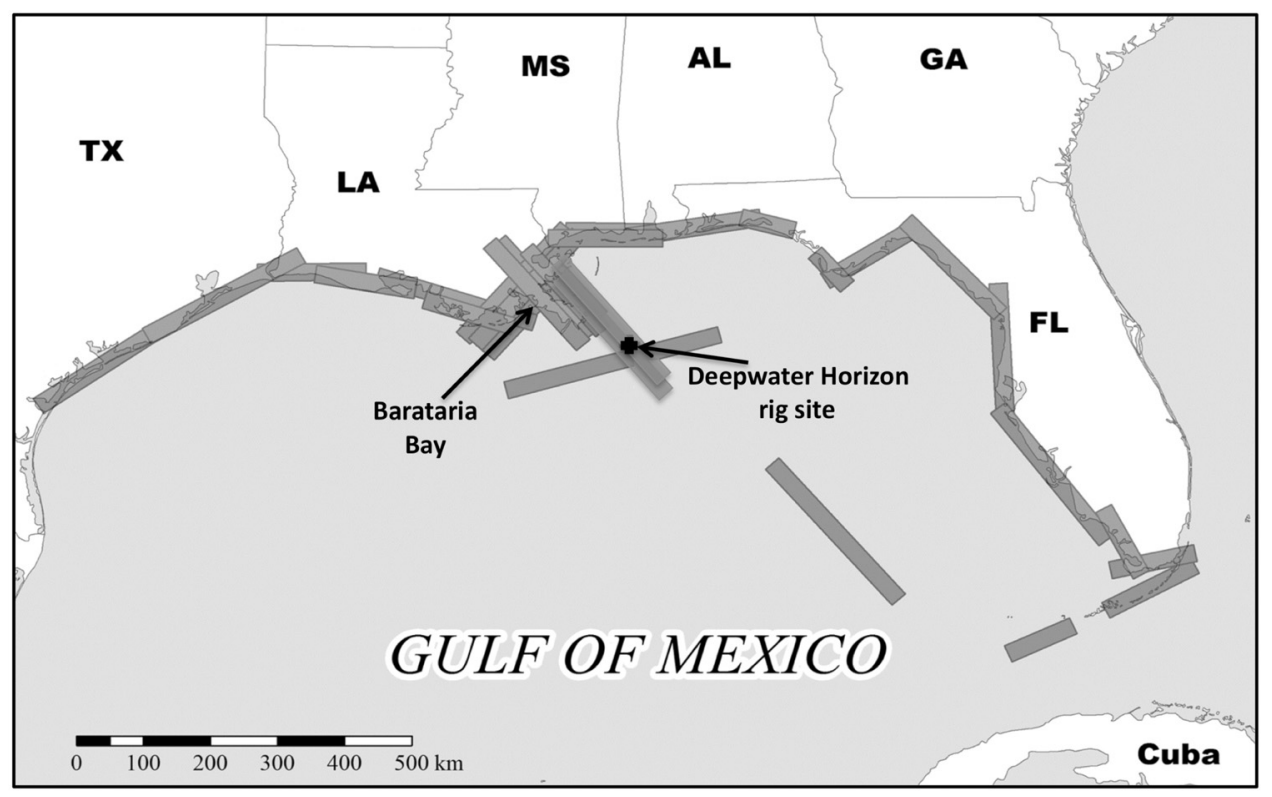

Figure 1. Map of the swaths where Uninhabited Aerial Vehicle Synthetic Aperture Radar (UAVSAR) data were collected during 22-23 June 2010 (http://uavsar.jpl.nasa.gov/index.html). The two eastmost lines over the alluvial fan of the Mississippi River delta, which had previously been collected in 2009 and early 2010, were extended during the flight to cover the Deepwater Horizon (DWH) rig site and the main slick in the Gulf of Mexico (GOM). 


\section{THE UAVSAR INSTRUMENT}

\subsection{Instrument Description}

UAVSAR is the latest generation of airborne SAR systems built by NASA's Jet Propulsion Laboratory to support a wide range of radar remote sensing studies using polarimetry (polarimetric SAR (POLSAR)) or differential interferometry (DifINSAR) [Hensley et al., 2008, 2009]. The UAVSAR radar is a miniaturized polarimetric synthetic aperture $\mathrm{L}$ band radar, operating with $80 \mathrm{MHz}$ bandwidth from 1217.5 to $1297.5 \mathrm{GHz}$ and deployed on the NASA Gulfstream-3 (G-3) aircraft. To allow instrument portability to alternate platforms, the radar electronics and antenna are housed in a pod mounted below the fuselage. The system is designed to have minimal interfaces with the aircraft and can operate in fully autonomous mode or accept commands from an operator either through an ethernet connection on crewed platforms or through an iridium modem on uncrewed platforms. The instrument uses both an embedded GPS inertial (EGI) navigation unit and a differential GPS (DGPS) unit to derive the antenna position, attitude, and velocity in real time.

UAVSAR is designed to measure surface deformation to $5 \mathrm{~mm}$ accuracy through repeat pass interferometric analysis of multiple data sets collected over a given area at different times. Robust repeat-pass radar interferometric measurement imposes two observational constraints on the UAVSAR radar and platform, namely, flight track repeatability and antenna steering capability. The NASA G-3 aircraft was modified at the Dryden Flight Research Center to include a Precision Autopilot system [Lin et al., 2008] to control aircraft position based upon high precision real-time position information provided by the DGPS unit. The aircraft normally flies within $5 \mathrm{~m}$ of the planned flight track. The system compensates for variations in the yaw and pitch angles of the aircraft, which arise from varying and different wind conditions aloft either within a single acquisition and on repeated tracks, by electronically steering the antenna beam in the desired look direction based on real-time attitude angle measurements derived from the EGI, thereby maintaining a constant look direction.

\subsection{Operating Mode During the Gulf Oil Spill Campaign}

The UAVSAR radar was operated in quad-polarization mode during the oil spill campaign, transmitting horizontally and vertically polarized radiation on alternate pulses and receiving both co-polarized (horizontal transmit and receive polarization $(\mathrm{HH})$ or vertical transmit and receive polarization (VV)) and cross-polarized horizontal transmit and vertical receive (HV) or vertical transmit and horizontal receive (VH) returns for each pulse. UAVSAR's swath width is
$22 \mathrm{~km}$, which illuminates an area from $22^{\circ}$ to $65^{\circ}$ incidence angle, with $3 \mathrm{~m}$ (cross-track average) by $1 \mathrm{~m}$ (along-track) single look ground resolution. The platform operated at $12.5 \mathrm{~km}$ altitude for all data collections during this campaign.

While we have used polarimetric SAR (POLSAR) analysis mode for the results reported here, it is worth noting that the repeat track capability of the UAVSAR system is of value for our application because it ensures that comparisons of the June 2010 data with earlier data from 2009 and any future acquisitions (now including June 2011) are not compromised by platform-induced incidence angle variations. This consideration is particularly important for vegetation studies because vegetation is more sensitive to baseline errors than other scattering media found in the GOM region.

\subsection{Instrument Performance for Oil Detection and Ecosystem Oil-Impact Assessment}

To understand the unique contribution of the UAVSAR radar to studies of the DWH spill, it is necessary to consider the characteristics of UAVSAR relative to other imaging systems in use at the time. Table 1 contains a comparison with several major sensor systems employed to image the oilaffected areas and with airborne synthetic aperture radar, which was UAVSAR's predecessor. For brevity, standard strip map data product characteristics are listed, although most of the more recent radar systems can operate in other imaging modes with trade-offs between swath, resolution, and number of transmitted and received polarizations. The relative importance of each parameter listed in the table depends upon the application; this is discussed in more detail below.

The signal levels of radar returns from water are significantly lower than from land in general [Valenzuela, 1978] and are further reduced when oil is present on the water surface [Fingas and Brown, 1997]. For imaging oil on water, the limiting factor in most radar systems is instrument noise, which we characterize by the noise equivalent sigma-zero (NESZ), given in Table 1, and discussed in greater detail in section 2.4. Variations in returns from oil on water that are above the instrument noise floor and cover an area greater than the instrument's spatial resolution can be discerned in SAR images. For oil slicks that cover large areas, the spatial resolution is less important than the instrument noise floor, though higher resolution allows greater discrimination between variations in the characteristics of the slick, as we show in section 4.1. When studying ecosystem impacts, spatial resolution is often the limiting factor because the affected areas along shorelines are likely to extend only a few to tens of meters inland.

Radar systems that operate in all four polarized channels (HH, VV, HV, and VH) maximize the amount of data available for a given pixel and enable the use of sophisticated data 
Table 1. Comparison of Sensor Systems' Standard Strip-Map Mode Data Products

\begin{tabular}{|c|c|c|c|c|}
\hline Sensor & $\begin{array}{l}\text { Description (Type, Band, } \\
\text { Wavelength, Polarization) }\end{array}$ & Swath Width (km) & $\begin{array}{l}\text { Product Geometric } \\
\text { Resolution }(\mathrm{m})\end{array}$ & $\begin{array}{l}\text { Noise Equivalent } \\
\text { Sigma-Zero (dB) }\end{array}$ \\
\hline $\begin{array}{l}\text { Uninhabited Aerial } \\
\text { Vehicle Synthetic } \\
\text { Aperture Radar }\end{array}$ & $\begin{array}{l}\text { Airborne SAR; L band; } \\
\text { quad polarization }\end{array}$ & 22 & 7 (multilook, 36 looks) & -35 to -53 \\
\hline ERS-1/2 & $\begin{array}{c}\text { Satellite SAR; C band; } \\
\text { VV polarization }\end{array}$ & 100 & 25 & -20 to $-29^{\mathrm{a}}$ \\
\hline Radarsat-2 & $\begin{array}{l}\text { Satellite SAR; C band; } \\
\text { single or dual polarization }\end{array}$ & 100 & 25 & $-29^{\mathrm{b}}$ \\
\hline $\begin{array}{l}\text { Envisat advanced } \\
\text { synthetic aperture radar }\end{array}$ & $\begin{array}{l}\text { Satellite SAR; C band; } \\
\text { single or dual polarization }\end{array}$ & 100 & 30 & -20 to $-29^{\mathrm{a}}$ \\
\hline $\begin{array}{l}\text { Advanced Land Observing } \\
\text { Satellite Phased Array } \\
\text { L-band Synthetic Aperture } \\
\text { Radar (ALOS PALSAR) }\end{array}$ & $\begin{array}{c}\text { Satellite SAR; L band; } \\
\text { single, dual, } \\
\text { or quad polarization }\end{array}$ & 70 & $\begin{array}{r}10 \text { (single polarization), } \\
20 \text { (dual polarization) }\end{array}$ & $\begin{array}{c}\text { average } \\
-23(\mathrm{HH} \text { or } \mathrm{VV}), \\
-26 \mathrm{~dB}(\mathrm{HV})^{\mathrm{c}}\end{array}$ \\
\hline TerraSAR-X & Satellite SAR; X band; & $\begin{array}{r}20 \text { (single polarization) } \\
15 \text { (dual polarization) }\end{array}$ & $\begin{array}{r}3.3 \text { (single polarization) } \\
6.6 \text { (dual polarization) }\end{array}$ & average $-23^{\mathrm{d}}$ \\
\hline $\begin{array}{l}\text { airborne synthetic } \\
\text { aperture radar }\end{array}$ & $\begin{array}{c}\text { Airborne SAR; C, L, } \\
\text { and P band; } \\
\text { quad polarization }\end{array}$ & 10 & 8 & $\begin{array}{l}-34 \text { to }-50 \mathrm{~dB}(\mathrm{~L}) ; \\
-40 \text { to }-48(\mathrm{P}) ; \\
-26 \text { to }-34(\mathrm{C})^{\mathrm{e}}\end{array}$ \\
\hline $\begin{array}{l}\text { Airborne Visible/Infrared } \\
\text { Imaging Spectrometer }\end{array}$ & $\begin{array}{l}\text { Airborne hyperspectral; } \\
224 \text { bands from } 400 \text { to } \\
2500 \mathrm{~nm}\end{array}$ & $\begin{array}{l}11 \text { (high altitude); } \\
1.9 \text { (low altitude) }\end{array}$ & $\begin{array}{l}20 \text { (high altitude); } \\
4 \text { (low altitude) }\end{array}$ & not applicable \\
\hline
\end{tabular}

${ }^{a}$ http://envisat.esa.int/handbooks/asar/CNTR3-2-1.htm.

${ }^{\mathrm{b}}$ RadarSAT-2 Product Description, RN-SP-52-1238, 2 Nov 2009.

${ }^{\mathrm{c}}$ ALOS PALSAR Cyclic Report-Cycle 13, PALSAR_CR_13_070723_070907, 10 Jan 2008.

${ }^{\mathrm{d}}$ TerraSAR-X Ground Segment Basic Product Specification Document, TX-GS-DD-3302, 2008.

ehttp://airsar.jpl.nasa.gov/documents/instrument.htm.

analysis techniques that derive information about the scattering surface or volume from the relative radar returns of the polarized channels [Lee and Pottier, 2009]. The polarization of electromagnetic radiation is completely described by two polarization states, e.g., $\mathrm{H}$ and $\mathrm{V}$ polarizations, in the plane perpendicular to the propagation direction. Co-polarized (HH or VV) returns measure mechanisms that preserve the polarization, and cross-polarized ( $\mathrm{HV}$ or $\mathrm{VH})$ returns are indicative of scattering mechanisms that induce orthogonal depolarization. The reciprocity theorem dictates that the two cross-polarized channels (HV and $\mathrm{VH}$ ) yield the same information in a monostatic radar system, and UAVSAR data are calibrated to match this principle.

Most satellite SAR data collected over the DWH oil spill were acquired in single or dual polarization mode, collecting copolarized returns only. To fully characterize the scattering mechanism from a surface, it is necessary to collect radar data for all co-polarized and cross-polarized channels and evaluate their relative contributions to the total backscatter [Cloude and Pottier, 1996]. Scattering from vegetation is polarization-dependent because the orientation, volume, and water content of the various parts of the plant determine the polarization of the scattered radiation, altering the relative contributions of the different polarizations to the return signal level. Full polarization is valuable for the open water studies because radar scattering from clean water involves a single, largely polarization-preserving, dominant scatterer, yielding cross-polarized returns that are negligible relative to the total returned power. For most instruments, the cross-polarized signal is below the instrument noise floor for returns from oil on water, making it unobservable.

Radar is an all-light, nearly-all-weather instrument, while optical instruments do not see below clouds and are limited by sun glint to certain observation times and imaging directions. Radar signals can be attenuated by rain and water vapor, an affect minimized at $\mathrm{L}$ band compared with shorter frequencies. The ionosphere also impacts radar signals, particularly for longer wavelengths including L band. The G-3 operational altitude is high enough for UAVSAR to experience most of the tropospheric attenuation of satellite radars, except that which is from high-altitude cumulonimbus clouds, but none of the ionospheric effects. A primary issue with SAR is that the reduced return signal from a mineral oil slick is similar to that from areas of low wind or biogenic slicks, but a low-noise floor plus multiple polarizations could help to resolve the differences. 
Sensors operating in the optical and thermal bands can be used to characterize the biological and chemical properties of the scattering surface, while radar instruments can be used to characterize the physical and dielectric properties of the surface, which may be altered by chemical and biological processes. Optical radiation scatters from the first encountered surface, while longer wavelength radiation can penetrate below the surface, depending upon the dielectric properties of the scattering medium. The longer wavelength $\mathrm{L}$ band radiation penetrates through vegetation canopy much better than $\mathrm{X}$ band or $\mathrm{C}$ band radar, potentially detecting oil impact below the canopy, which is not possible with optical or short wavelength radar sensors and is particularly important in marshes where dense vegetation is typical. We include the characteristics of AVIRIS in Table 1 as an example of an optical sensor that was used to study the DWH oil spill, albeit not concurrent with the UAVSAR overflights.

\subsection{UAVSAR NESZ}

A central parameter for radar remote sensing instruments is the minimal detectable reflected signal from the surface. This is usually quantified in terms of NESZ, which is the backscatter level of the surface that would equal the amount of background noise present in a radar resolution element. Noise in a radar resolution element has two components, additive and multiplicative, and depends on the transmitted power, antenna gain, losses in the system, and operating temperature.

Additive noise is primarily due to thermal noise and comprised of contributions from the electronics and from the background environment. All objects with temperatures above absolute zero emit radiation spanning the electromagnetic spectrum due to the vibration of electrons, with the strength of the emitted radiation directly proportional to the temperature. The emitted radiation at frequencies that overlap the radar receiver's operational bandwidth gives rise to the thermal noise sensed by the instrument. Additive noise is independent of the strength of the echoes reflected from the ground.

Multiplicative noise refers to noise sources that depend on the strength of the reflected signal, predominantly quantization noise, ambiguities, and impulse response sidelobes. Quantization noise results from the finite number of bits used to record the strength of the reflected signals, effectively 8 bits for UAVSAR. The smaller the number of bits used to encode the signal, the greater the amount of quantization noise due to the loss of signal information. Ambiguities are ghost signals originating from points outside the resolution element that are received because of the finite time interval between pulses. There are two types of ambiguities, range and azimuth, although only azimuth ambiguities are relevant for UAVSAR.

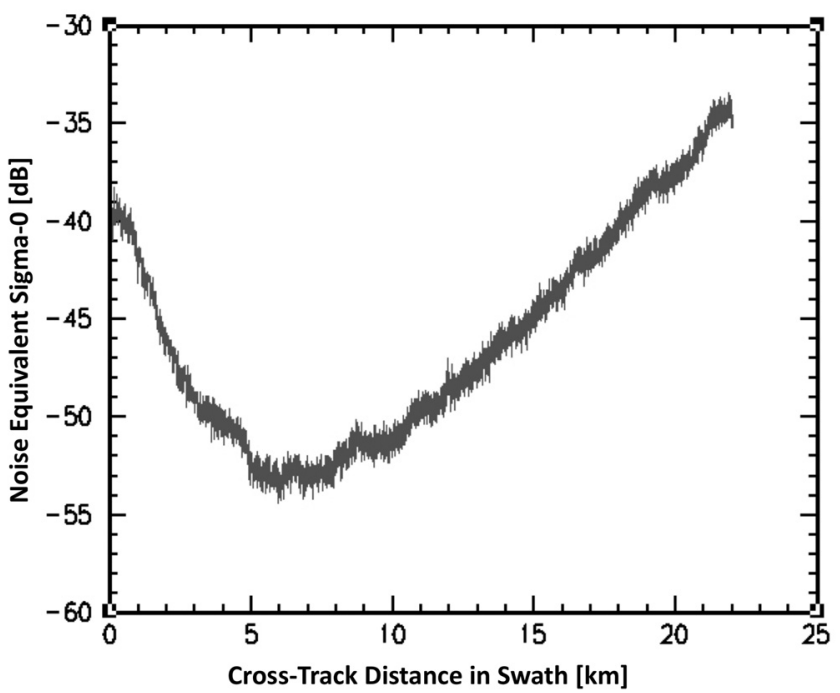

Figure 2. Noise equivalent sigma-zero of the UAVSAR L band radar as a function of cross-track distance (ground range) across the swath.

Insuring the radar emits pulses at a sufficiently high frequency controls azimuth ambiguity levels. Impulse response sidelobes are a form of ghost energy that results from the range and azimuth sampling being finer than the actual instrument resolution and the finite spectral support of the signals.

The NESZ of the UAVSAR radar was measured using socalled sniffer pulses, whereby the radar operates in receiveonly mode. In this mode, the radar records only thermal noise and background radio frequency interference. Sniffer pulses are processed identically to radar echo data, and the resulting measured signal level is the NESZ of the system, which includes all the aforementioned noise sources except azimuth ambiguities. Figure 2 shows the NESZ as a function of range, which is $-53 \mathrm{~dB}$ at the point of maximal antenna gain and degrades to $-40 \mathrm{~dB}$ in the near and far range $(-35 \mathrm{~dB}$ at the far swath limit). A typical radar-dark surface with $L$ band backscatter value of $-30 \mathrm{~dB}$ has a UAVSAR signal-to-noise ratio in excess of $10 \mathrm{~dB}$ over most of the swath, but would be near or below the noise floor in the other related systems (Table 1). Thus, the low-noise floor of UAVSAR provides a unique capability to assess backscatter information at levels not available with other radars.

\section{OIL SPILL DETECTION WITH THE UAVSAR RADAR}

\subsection{Theory of Radar Response to Oil on Water}

A microwave signal impinging on a surface will, in general, scatter energy in all directions, with the signal reflected 
back toward the microwave sensor or radar referred to as the backscatter. The amount of backscattered energy is a function of a number of parameters including the polarization of the microwaves. Radar waves are a form of electromagnetic radiation and have both a magnitude and direction. Polarization is defined by the direction of the electric field component of an electromagnetic wave and can point in either a fixed direction, called linear polarization, or more generally trace out an elliptical path during propagation (elliptical polarization). The scattering of polarized electromagnetic radiation depends on the orientation of objects from which they scatter and, thus, provides enhanced information about the scene under observation. By transmitting and receiving horizontal and vertical polarized waves, it is possible to synthesize all other possible combinations of transmit and receive polarizations. Looking at various polarization combinations or at quantities that can be computed from the various polarizations is useful for determining quantitative information about a surface.

Radar returns from water are typically lower intensity than from land and can be approximated to first order as Bragg scattering from the small gravity-capillary waves on the water surface [Wright, 1968; Valenzuela, 1978]. In the Bragg scattering model, the roughness is small relative to the wavelength of the radar and randomly distributed on the scattering surface. These small height perturbations generate primarily co-polarized backscatter and negligible depolarization. Cross-polarized backscatter arises through a contribution due to the sea surface tilt caused by long wavelength gravity waves and is a function of the difference between the $\mathrm{HH}$ and VV co-polarized returns [Valenzuela, 1978]. In first-order Bragg scattering theory, only ocean waves with wavenumber

$$
k_{B}=2 k_{r} \sin \left(\theta_{i}\right)
$$

contribute to the radar backscatter, where $k_{r}$ is the radar wavenumber, and $\theta_{i}$ is the radar incidence angle at the surface. In actuality, the scattering return from water is a complex function of the imaging geometry, the ocean wave spectrum, which is affected by swell, wind, and mechanisms that transfer energy between different parts of the wave spectrum, and the dielectric properties of the surface.

Marine slicks dampen the short wavelength ocean waves, reducing the radar return beyond the already low return from water [Fingas and Brown, 1997; Gade et al., 1998a]. The main damping mechanism for the small-scale capillary and gravity-capillary waves results from a reduction in the surface tension at the air-liquid interface. This can be shown by examining the dispersion relationship for waves of angular frequency $\omega$ and wavenumber $k$ at the interface between air and a liquid of density $\rho$ and surface tension $\sigma$, which is

$$
\omega^{2}=g k+(\sigma / \rho) k^{3},
$$

where $g$ is the acceleration due to gravity. Equation (2) is the general expression for gravity-capillary waves, with gravity waves defined by the limit for small wavenumber, $\omega=\sqrt{g k}$, and capillary waves defined by the limit for large wavenumber, $\omega=\sqrt{(\sigma / \rho) k^{3}}$. Both the density and surface tension of oil is less than those of water, with oil generally being in the range $\rho_{\text {oil }} \sim 0.8-0.9 \rho_{\mathrm{H} 20}$ and $\sigma_{\text {oil }} \sim 0.35-0.5$ $\sigma_{\mathrm{H} 20}[$ Harvey, 1925]. In an actual slick, the surface characteristics will vary between the slick-free water values and the oil values depending upon the layer thickness and fractional surface coverage, but the general trend can be understood by considering equation (2) in more detail. Ocean waves are excited by resonant forcing in a turbulent wind field [Phillips, 1957], where equilibrium is reached when the wind speed matches the wave's phase velocity,

$$
c=\omega / k=\sqrt{g / k+(\sigma / \rho) k} .
$$

For water, equation (3) gives a minimum phase velocity of $0.23 \mathrm{~m} \mathrm{~s}^{-1}$ at $1.7 \mathrm{~cm}$ wavelength. The lower surface tension at the air-oil interface will reduce the minimum phase velocity with a corresponding decrease in the wavelength of the minimum energy excited waves; for example, the minimum phase velocity is $0.20 \mathrm{~m} \mathrm{~s}^{-1}$ at $1.2 \mathrm{~cm}$ wavelength if the oil-to-water density ratio is 0.9 and surface tension ratio is 0.45 . Therefore, for a given wind field, the wave spectrum will be shifted to smaller wavelengths when oil is present on the surface, changing the roughness of the surface. The change in surface tension can also affect the longer wavelength components of the ocean wave spectrum through gradients in the surface tension (Marangoni effect) and indirectly through nonlinear wave-wave interactions that shift energy between different wavenumber components of the spectrum [Alpers and Hühnerfuss, 1988; Gade et al., 1998a, 1998b]. A rigorous theoretical analysis of wind wave growth in the presence of a surface film is given by Creamer and Wright [1992].

The surface of a slick appears smoother than the windroughened surface of the surrounding clean water. Suppression of radar returns by oil increases with increasing radar frequency, e.g., $\mathrm{Ku}$ band is more sensitive than $\mathrm{L}$ band [Wismann et al., 1998]. Previous studies have found that mineral oil slicks are detected when wind speeds are between 3 and $14 \mathrm{~m} \mathrm{~s}^{-1}$, depending on the oil properties [Wismann et al., 1998; Wahl et al., 1996; Espedal et al., 
1998; Espedal and Wahl, 1999; Brekke and Solberg, 2005]. Donelan and Pierson [1987] concluded that significant Bragg scatter is observable at $\mathrm{L}$ band for minimum wind speeds between 1.6 and $2.0 \mathrm{~m} \mathrm{~s}^{-1}$ based on a model of the wind field's vertical profile and the ocean waves' dispersion relationship. In practice, an instrument's noise floor determines the actual minimum wind speed at which Bragg scattering is observed because the wind speed must be high enough to generate a backscatter signal above the instrument noise. For the UAVSAR data, the Bragg scattering wavelength is $27.1 \mathrm{~cm}$ in the near range and $13.2 \mathrm{~cm}$ in the far range, both of which are short wavelength gravity waves. Radar backscatter at these wavelengths is expected to be low, especially in the relatively quiet waters of Barataria Bay, requiring a low-noise instrument to measure accurately.

We have used the multiple polarizations of the microwave radiation to study the oiled surface characteristics. Analysis of radar information is made more tractable by looking at various metrics distilled from the infinite number of possible polarization combinations that capture key elements of the scattering signature from surfaces. Our analysis of the UAVSAR data relies largely on an eigenvector-based polarimetric decomposition that is an adaptation of the $\mathrm{H} / \mathrm{A} / \alpha$ method developed by Cloude and Pottier [1997] to include the averaged intensity introduced by Fang and Wen [2005]. The polarimetric decomposition identifies which polarization combinations contribute to the scattered radiation from a pixel on the ground and hence increases the ability to discriminate subtle contrast features induced by oil contamination that alters the polarization of the returns. A brief heuristic description of the key parameters we found most useful in our analysis, namely, the averaged intensity, $\Lambda$, entropy, $H$, and anisotropy, $A$, is provided here, and detailed definitions of these parameters from the radar scattering amplitudes are included in Appendix A. The averaged intensity of a pixel is the weighted mean of the intensities of the different scattering mechanisms from the surface within a resolution cell and is related to the total radar return power. Over water, we expect a single dominant scatterer, which means the averaged intensity is approximately equal to the total radar return power. Entropy measures the uniformity of the scattering mechanism; low entropy means there is one dominant scattering mechanism, e.g., surface or volume scattering, whereas high entropy means there is a mixture of comparable strength scattering mechanisms. The anisotropy is a measure of the importance of the contribution from secondary scattering mechanisms to the radar signal. Increasing anisotropy generally indicates increasing amounts of multiple scattering, although a physical interpretation is not always obvious.

\subsection{Detection of Oil in the Main Slick of the DWH Spill}

Our previous analysis of UAVSAR data acquired over the DWH site showed that the ability to distinguish oil from clean water with $\mathrm{L}$ band radar increases with incidence angle due to the suppression of small capillary waves that cause Bragg scattering. When the polarized channels are considered individually, the vertical co-polarized channel (VV) shows the most prevalent distinction between oil and water at all but the lowest observed incidence angles (those below approximately $35^{\circ}$ ). As the incidence angle increases from approximately $22^{\circ}$ to $65^{\circ}$, the oil-versus-water distinction increases in the co-polarized channels ( $\mathrm{HH}$ and VV), with the amplitude of the return from oil decreasing more rapidly than the return from clean water, but changes little in the cross-polarized channel (HV). This causes the backscatter to have an apparent depolarization signal that increases with incidence angle despite the fact that oil slicks smooth the small capillary waves on the water's surface. Our previous analysis showed that cross-polarized returns from the relatively smooth surfaces of oil slicks contribute a non-negligible amount of the total return power.

A conclusion of our previous analysis is that the UAVSAR radar has sufficiently low noise to detect oil in the main slick in $\mathrm{HH}, \mathrm{VV}$, and $\mathrm{HV}$ polarization channels. The limiting factor is the HV signal, which is $\sim 10 \mathrm{~dB}$ below the $\mathrm{HH}$ and VV signal levels and is above the instrument noise floor at incidence angles $<55^{\circ}$. Our previous analysis also indicates that the averaged intensity and, possibly, the anisotropy (at incidence angles $<50^{\circ}$ ) are best suited to differentiate variations in the oil on the sea surface within the main DWH slick near the rig site and that entropy does not show favorable distinguishing characteristics in that area.

\subsection{Sensitivity of UAVSAR to Oil Characteristics}

Although to date, radar has mainly been used to identify areas with slicks without further characterization of the type or amount of oil in the slick, some previous measurements have suggested that radar might be sensitive to oil thickness from observations of the windward edge of a mineral oil slick where the oil becomes bunched by the wind [Gade et al., 1998b] and to weathering of crude oil [Alpers and Hühnerfuss, 1988]. Because of the vast amounts of oil being continuously released, the oil within the DWH slick was more varied than in previously studied slicks. Furthermore, the slick extended across a much larger area in the ocean and included areas with greater surface oil thickness, all of which contribute to distinguishing studies of the DWH spill from previous work on radar detection of mineral oil slicks. 
To determine whether a low-noise radar could potentially be of use in characterizing oil properties within a large slick, we have looked for variations in the $\mathrm{H} / \mathrm{A} / \Lambda$ parameters within the main oil slick and compared the UAVSAR sensitivity to that of other radars. In the UAVSAR polarimetric decomposition analysis of the main slick, the entropy parameter shows little variation except at large incidence angles, and the anisotropy has much more noise because of the low HV signal level. Therefore, we focus here on the averaged intensity, $\Lambda$, as the parameter likely to be most useful for differentiating different types of oil within the slick. Figure 3 shows UAVSAR averaged intensity maps of several areas within the main slick within $40 \mathrm{~km}$ of the DWH rig site (3AC) and photographs taken of the area on the same day as the UAVSAR collections (3D). The UAVSAR images have $7 \mathrm{~m} \times 7 \mathrm{~m}$ spatial resolution. Boats near the DWH rig site, which normally show up in radar images as bright scatterers that overwhelm the return from the water in their vicinity, appear here as dark areas due to our choice of color scale, which has clean water being blue. Figure $3 b$ shows the leeward side of the slick $\sim 31 \mathrm{~km}$ north-northwest of the rig site, and Figure $3 \mathrm{c}$ shows the windward side of the slick $\sim 25 \mathrm{~km}$ southwest of the rig site. At the time of the overflight (21:00 UTC), the closest directional buoy, Station 42012 $\left(30.065^{\circ} \mathrm{N}, 87.555^{\circ} \mathrm{W}\right)$, gave a wind direction of $120^{\circ} \pm 6^{\circ}$, wind speed $2.5-5.0 \mathrm{~m} \mathrm{~s}^{-1}$, significant wave height $0.6 \mathrm{~m}$, and ocean temperature of $31.2^{\circ} \mathrm{C}$. The smooth edge on the windward side and the dispersing oil on the leeward edge indicate the wind direction and agree with the buoy data.

For a validation data set, we use photos taken by NOAA RAT and TAC helicopter and EPA/Airborne Spectral Photometric Environmental Collection Technology (ASPECT) crews who observed the slick within 0.5 to $4 \mathrm{~h}$ of the UAVSAR collection. While the slick undoubtedly moved during the intervening time, the general features and some specific areas seen in the photos are identifiable in the UAVSAR image. This comparison is shown in Figure 3 and includes areas with high averaged intensity values where photographs show an oil-depleted surface in the wake of a ship (feature $i$ ), oil collected along the leeward and windward edges (features $i i, i v$ ), low intensity/high entropy areas with the shape and size of brown-black emulsion (features iii, iv), and oil collected along Langmuir circulation cells (feature $v$ ). Good agreement between photos and radar is seen, showing that low-noise radar can be used to classify oil within a slick, not just discriminate oil-on-water from clean water.

Of particular note is the oil collected into windrows formed by Langmuir circulation [Leibovich, 1983]. Langmuir circulation is an atmospheric boundary layer convective wind pattern on the ocean surface that is comprised of individual elongated cells with alternating convergent and divergent rotational circulation that line up with the wind direction. Oil and short wavelength ocean waves tend to accumulate within the convergent zones and disperse in the divergent zones between adjacent cells. In the UAVSAR data, we see a distinct change in the intensity of the surface within the Langmuir cells. Without any oil present, the convergent zones would nominally have slightly higher intensity than the adjacent divergent zones. However, in this extensive and thick slick, the convergent zones are more likely to contain more oil than the divergent zones and at sufficient concentration to suppress the accumulated short waves and thus appear with reduced intensity compared to adjacent divergent zones. The process of surfactants accumulating within convergent zones of Langmuir cells has been previously identified [Marmorino et al., 2008].

Our results indicate that the radar can be used for detecting varying concentrations of oil and potentially oil thickness in the low-intensity scale range. Further study of the polarization dependence is needed to determine whether differences

Figure 3. (opposite) (a-c) The averaged intensity in and near the main slick of the DWH spill derived from the $7 \mathrm{~m}$ resolution multilook POLSAR data, plotted in radar coordinates with the cross-track direction from left to right $(a, b)$ or right to left (c), for UAVSAR flight lines (a, b) gulfco_14010 (23 June 2010 20:42 UTC) and (c) gulfco_32010 (23 June 2010 21:08 UTC) (see Figure 1 for approximate locations). Ground swaths shown are 11-16 km wide. The images show a range-dependent trend from higher to lower returns as the incidence angle increases. Here we consider small-scale variations within the spill: (a) Windward side of the main oil slick in the vicinity of the DHW rig site. Feature (i) is a high intensity line (reduced surface oil) in the wake of a ship (photo D-1, NOAA RAT-Helo-935AL-6-23-2010_430, 23 June 2010 19:53 UTC). Features (ii) are shown in photo D-4 (NOAA RAT-Helo-935AL-6-23-2010_431, 23 June 2010 19:53 UTC) to be an area with little surface oil area just inside the leeward edge of the slick to the west of the DWH rig site and a cloudy band along the windward edge near the rig site that is probably from dispersants. We see a lower-intensity band in the radar image in this region, with a particularly radar-dark spot nearest the rig. Features (iii) are low-intensity streaks similar to brown-black emulsion streamers observed within the slick (photo D-3, NOAA EPA/ASPECT 55_055, 23 June 2010 16:50 UTC). (b) Leeward side of the main slick 31 km NNW of the rig site. Features (iv) are low intensity accumulations of oil along the leeward edge, similar to brown-black emulsion that shows up along the edge of thin sheen areas (photo D-4, NOAA EPA/ASPECT 55_053, 23 June 2010 16:50 UTC). (c) Windward side of the main slick, $26 \mathrm{~km} \mathrm{SW}$ of the rig site. Features (v) are Langmuir cells forming streaks along the wind direction (photo D-5, NOAA RAT-Helo935AL-6-23-2010_421, 23 June 2010 19:45 UTC). 

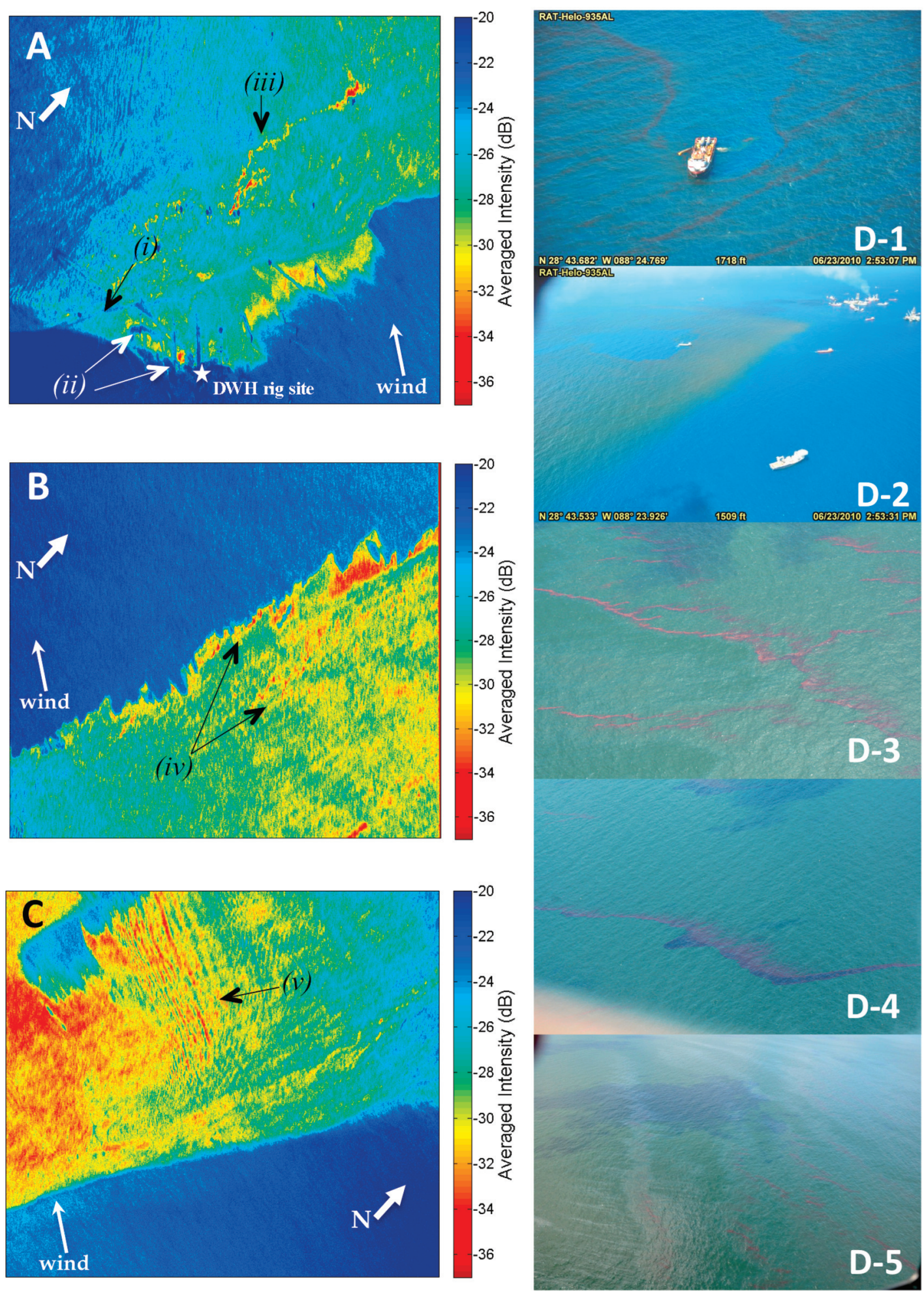

Figure 3 
in oil thickness can be distinguished from differences in oil emulsification, since both variations in the oil characteristics show up as changes in the averaged intensity.

For comparison to a satellite SAR image of the slick, Figure 4a shows an ERS-2 image, collected with $25 \mathrm{~m}$ resolution on 22 June 2010, that covers the western portion of the slick areas shown in Figure 3. There is reduced variation on backscatter within the primary spill area compared to UAVSAR, with windrows also detectable extending from the downwind edge of the primary slick region and elsewhere in the image.

All features mentioned in the UAVSAR images shown in Figure 3 covered multiple pixels, indicating uniformity in the surface oil over more than $30 \mathrm{~m}$ distance. This is not to imply that the surface oil within a resolution cell was uniformly thick or emulsified at a very small scale because features smaller than the $7 \mathrm{~m}$ pixel resolution cannot be identified unless they dominate the backscatter. However, regions that are more like clean water (bluer in image) and those more like heavy oil (yellow to red) are identifiable in the images. Therefore, we conclude from this data that low-noise radars with moderate resolution could be of use in identifying areas with different types (emulsification, weathering, dispersants) and amounts (fractional coverage, thickness) of oil. Further study with concurrent surface observation and preferably with constrained oil properties are warranted.

\section{OIL IMPACT MAPPING IN SOUTHERN LOUISIANA}

\subsection{Oil Detection in Coastal Waterways}

NOAA oil trajectory maps (http://www.noaa.gov/ deepwaterhorizon/maps/) prepared by the National Environmental Satellite, Data, and Information Service indicate that oil moved into Barataria Bay (BB) on or around 16 June 2010 and remained in the area, with some oil still present on 23 June 2010 in the northeast, centered around Bay Jimmy. Visual observations made from a boat in Barataria Bay on 23 June 2010 indicate that the oil in this area was mostly light sheen with some areas of emulsified oil along shorelines and booms (Bruce Davis, private communication, 2010). UAVSAR acquired data along three flight lines that cover parts of Barataria Bay from different look directions in June 2010, one of which was a repeat of a line collected in June 2009. Meteorological data collected at buoy station TRBL1 $\left(29.167^{\circ} \mathrm{N}\right.$, $90583^{\circ} \mathrm{W}$ ) at the time of the flight measured a wind direction from $117^{\circ} \pm 5^{\circ}$ and wind speeds of 2.1-3.6 $\mathrm{m} \mathrm{s}^{-1}$.

Polarimetric images of Barataria Bay from the four June 2009 and June 2010 lines are shown in Figure 5 in radar coordinates, not ground referenced. (The reader should note that the use of the slant range in the look direction causes the

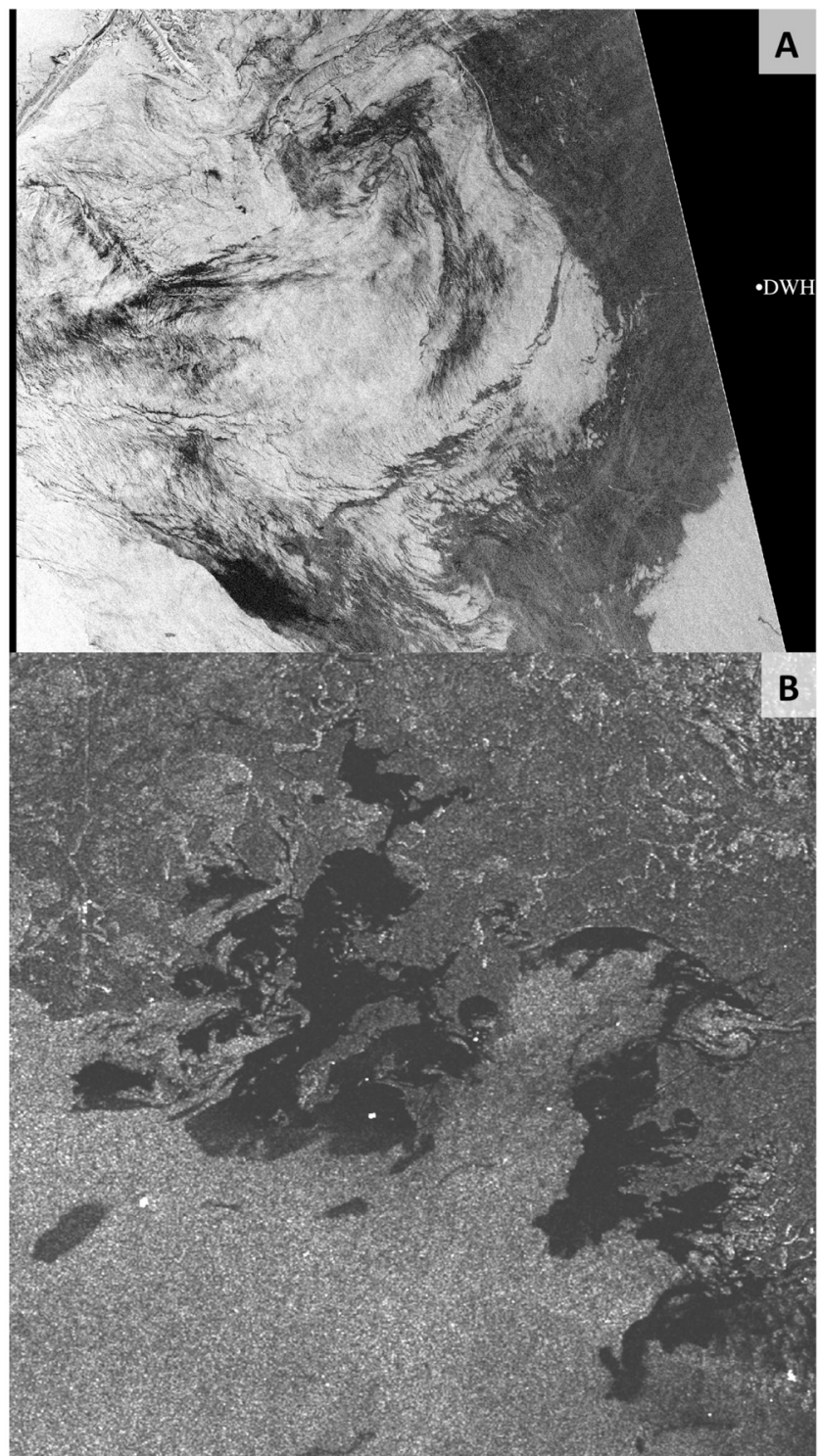

Figure 4. ERS-2 SAR images of (a) the main slick near the DWH rig site (22 June 2010 04:19 UTC), which covers an area approximately $65 \mathrm{~km}$ by $75 \mathrm{~km}$. (b) Barataria Bay (BB) (22 June 2010 16:38 UTC) which covers an area approximately $15 \mathrm{~km}$ by $15 \mathrm{~km}$ (Copyright European Space Agency, 2010).

apparent geometric distortion between the different views of the area.) Figure 5a shows the polarimetric returns from 2009 and Figures 5b-5d those from 2010, in time order with the earliest collected line shown in Figure 5b. Figure 5e shows the islands at the entrance to Barataria Bay from the GOM. During the time interval that the data was collected, the tide was going out in the bay, and water levels were near low tide. The 2009 image of the interior bay shows long streaks of oil/ 




Figure 5. UAVSAR multipolarization images of Barataria Bay (BB), Lousiana (red, HH; green, HV; blue, VV). Flight lines, radar coordinate directions, and acquisition times are indicated for each line. Images over the Bay Jimmy/Bay Batiste/Wilkinson Bay area in the northeastern part of the BB are (a) June 2009, 320 flight track heading; (b) June 2010, $320^{\circ}$ flight track heading, repeat of line shown in (a); (c) June 2010, $222^{\circ}$ flight track heading; and (d) June $2010,42^{\circ}$ flight track heading. (e) Image of the barrier islands at the entrance to BB; BB is in the upper part of the image.

surfactant, while the 2010 images of the same area show extensive radar dark patches that correlate well with areas reported by NOAA to have DWH oil at the time. Near the entrance to the bay (Figure 5e), similar radar-dark areas show up along some of the barrier islands. An ERS-2 image of Barataria Bay at $25 \mathrm{~m}$ resolution obtained on 22 
June 2010 (Figure 4b) shows oil in the same general location of the bay.

Owing to the location of the DWH site and the conditions in the GOM in the days prior to and during the UAVSAR data acquisition, oil near the coast and within the coastal waterways was at least several days older than the oil imaged near the spill site, with the oil in the inner bay likely to be 5-7 days old (http://www.noaa.gov/deepwaterhorizon/maps/). During this time, the oil would have undergone weathering, evaporation, and emulsification, among other processes, which alter the oil's physical and chemical properties. Once near the shore, and especially when inside a relatively sheltered bay, the oil would have mixed with suspended sediment and other surfactants, further altering its bulk physical properties [National Research Council, 2003].
The evolution of oil properties from near-source to nearshore is seen in the UAVSAR-derived $\Lambda$ /entropy image of the barrier islands of Barataria Bay (Figure 6). In this image, we can see that oil on the GOM side of the barrier islands (class A in Figure 6) shows a distinctly different signal (low intensity, low entropy) than oil on the bay side of the islands (class B, higher entropy). For oil in the inner bay, this disparity becomes amplified as the oil continues to accumulate sediment and other surfactants (class C).

While our previous study of UAVSAR data collected over the DWH site showed a strong incidence angle dependence in the radar properties of oil compared to water, the differentiating characteristics between the three oil classes A, B, and $\mathrm{C}$ show little or no incidence angle dependence. Instead, the entrainment of sediment and other surfactants, which is a


Figure 6. (left) Image showing the averaged intensity, $\Lambda$, (green) and entropy (red) from the Cloude-Pottier polarimetric decomposition in the vicinity of the barrier islands at inlet to BB, Louisiana. Class A is defined as weathered oil on the GOM side of the barrier islands, presumably on its first approach; class B is oil on the immediate bay side of the barrier islands that has partially mixed with sediment and other surfactants; and class $\mathrm{C}$ is oil that is heavily mixed with sediment and other surfactants that has moved into the interior bay. The yellow dashed line shows constant incidence angle for reference to oil areas $\mathrm{A}$ and $\mathrm{B}$. (right) $\Lambda$ (top) and entropy (bottom) plotted as a function of incidence angle for clean water in the GOM and in BB, oil in the main slick near the DWH site (DWH oil), and oil classes A, B, and C. The radar properties of oil in the main slick and in the different classes of oil close to shore are distinctly different and relate directly to proximity to land and exposure to wind, waves, and currents. 
function of proximity to land, season, and currents, appears to be the dominating factor in altering the radar scattering properties, as can be seen in Figure 6. The image on the left in Figure 6, which covers approximately the same area as Figure $5 \mathrm{e}$, is shown in radar coordinates and oriented on the page such that incidence angle decreases from $67^{\circ}$ on the left side of the image to $45^{\circ}$ on the right side. Consider the vertical dashed line that bisects the two letter As in Figure 6, which is a line of constant incidence angle. To the right of this line, the oil that is farther out from shore (in the mass associated with the upper letter A), has higher $\Lambda$ values (not as dark, quantified in top graph on the right) and lower entropy values (little-to-no red, quantified in bottom graph on the right) than oil that is closer to shore at approximately the same incidence angle. To the left of the line, the areas in class $A$ have similar $\Lambda$ and entropy values and approximately the same proximity to a barrier island. However, in the northernmost area of oil (topmost area B), we find that the $\Lambda$ and entropy values differ from class $\mathrm{A}$ oil at the same incidence angle. To evaluate class $\mathrm{C}$ oil, located far into the interior of Barataria Bay, we use the $\Lambda$ and entropy values for the area observed at different incidence angles in two different UAVSAR flight lines. These averaged intensity and entropy values are shown on the plots in Figure 6 for oil areas $\mathrm{A}, \mathrm{B}$, and $\mathrm{C}$; oil near the DWH rig site (red line) and clear water from the GOM near the DWH rig site (blue line) and within Barataria Bay (blue diamonds). For the "clear" Barataria Bay waters, we chose areas with backscatter levels similar to those measured in June 2009, which is our baseline for pre-DWH-oil water conditions in the bay. It is interesting to note that the backscatter in the clear bay waters is very similar to the backscatter from clear water in the open Gulf.

Entropy and $\Lambda$ data from representative samples of the three oil classes, the slick near the DWH site (labeled DWH oil), and clear water from near the main slick (GOM) and in Barataria Bay near Bay Jimmy (BB) show a profound difference in the radar properties as the fresh oil near the spill site evolves into weathered oil on approach to the shore (Class A). Through wind and current transport, oil previously in class A has drifted to the bay side of the barrier islands (Class B) and then eventually to deep within the bay (Class C). The averaged intensity becomes increasingly small as oil from the main slick evolves and migrates along the ocean surface, releasing its volatiles, emulsifying, and undergoing weathering. As the intensity decreases, the entropy increases, signifying that the randomness of the scatterers increases as the oil becomes weathered and likely combines with sediment and other surface contaminants commonly found in the bays of the GOM. This decrease in $\Lambda$ and increase in entropy occurs when all three polarimetric channels are above UAVSAR's noise floor, suggesting that oil has a more concentrated presence at the surface as it moves close to shore, while weathered oil that is still some distance from the shore (class A) is detectable due primarily to its attenuation of the ocean waves. This attenuation is likely evident near the barrier islands of Barataria Bay because of the shallow bathymetry and may be undetectable in deeper waters.

\subsection{Studies of Oil-Impacted Vegetation}

A ground survey in the Bay Jimmy, Batiste Bay, and Wilkinson Bay areas of Barataria Bay indicated that there was extensive oiling of vegetation along the shoreline of the radar-dark areas in Figure 5 (high entropy areas in Figure 6). A thorough study of the UAVSAR data to characterize the effects of oiling on the vegetation throughout the area, including a detailed comparison with the 2009 baseline data (Figure 5a), is being undertaken elsewhere (E. Ramsey et al., Oil detection in a coastal marsh with polarmetric SAR, submitted to Remote Sensing, 2011, hereinafter referred to as Ramsey et al., submitted manuscript, 2011); here we focus on one area in Bay Batiste (shown in white box in Figure 5b) for which we have ground truth data as an example of polarimetric decomposition analysis to identify areas of impacted marshland. An $\mathrm{H} / \mathrm{A} / \Lambda$, eigenvalue decomposition of the POLSAR data is shown in Figure 7 (top left), plotted as the averaged intensity, $\Lambda$, in green, entropy, H, in red, and anisotropy, A, in blue. The bright $\mathrm{red} /$ pink areas in the Figure 7 image have high entropy/low intensity and correspond to oil on the water; the bright green and yellow indicate land (largely vegetated); and the small dark or blue spots within the red areas are due to low entropy returns corresponding to water without sufficient oil on the surface to significantly damp the radar return. The small bright blue dots offshore near transect $\mathrm{A}$ are poles that hold booms in place.

The $\mathrm{H} / \mathrm{A} / \Lambda$ values along transects through the islands are plotted on the upper right of Figure 7. Photos of the southern shoreline at transect A (Figure 7, bottom left) and extending along the shoreline to the east (Figure 7, bottom right) were taken on 23 June 2010 (17:00 UTC). These photos document mixed shoreline conditions with areas where there was heavy mousse and emulsified red-brown oil on the surface, areas with dead vegetation, and areas of live vegetation that show oiling of the lower stalks only. The vegetation type is mixed in this area also. The water along the shoreline contains emulsified oil in a surface layer extending several meters offshore. High tide $(+1.3 \mathrm{ft})$ at the Manilla station in north Barataria Bay was at 23 June 2010 16:22 UTC, and low tide $(-0.3 \mathrm{ft})$ at 24 June 2010 04:33 UTC; at Grand Isle at the entrance to Barataria Bay, high tide $(+1.4 \mathrm{ft})$ was at 23 June 2010 13:50 UTC and low tide $(-0.3 \mathrm{ft})$ at 24 June 2010 01:20 UTC. Tides at the location shown would have been intermediate between times at these two stations. Between 

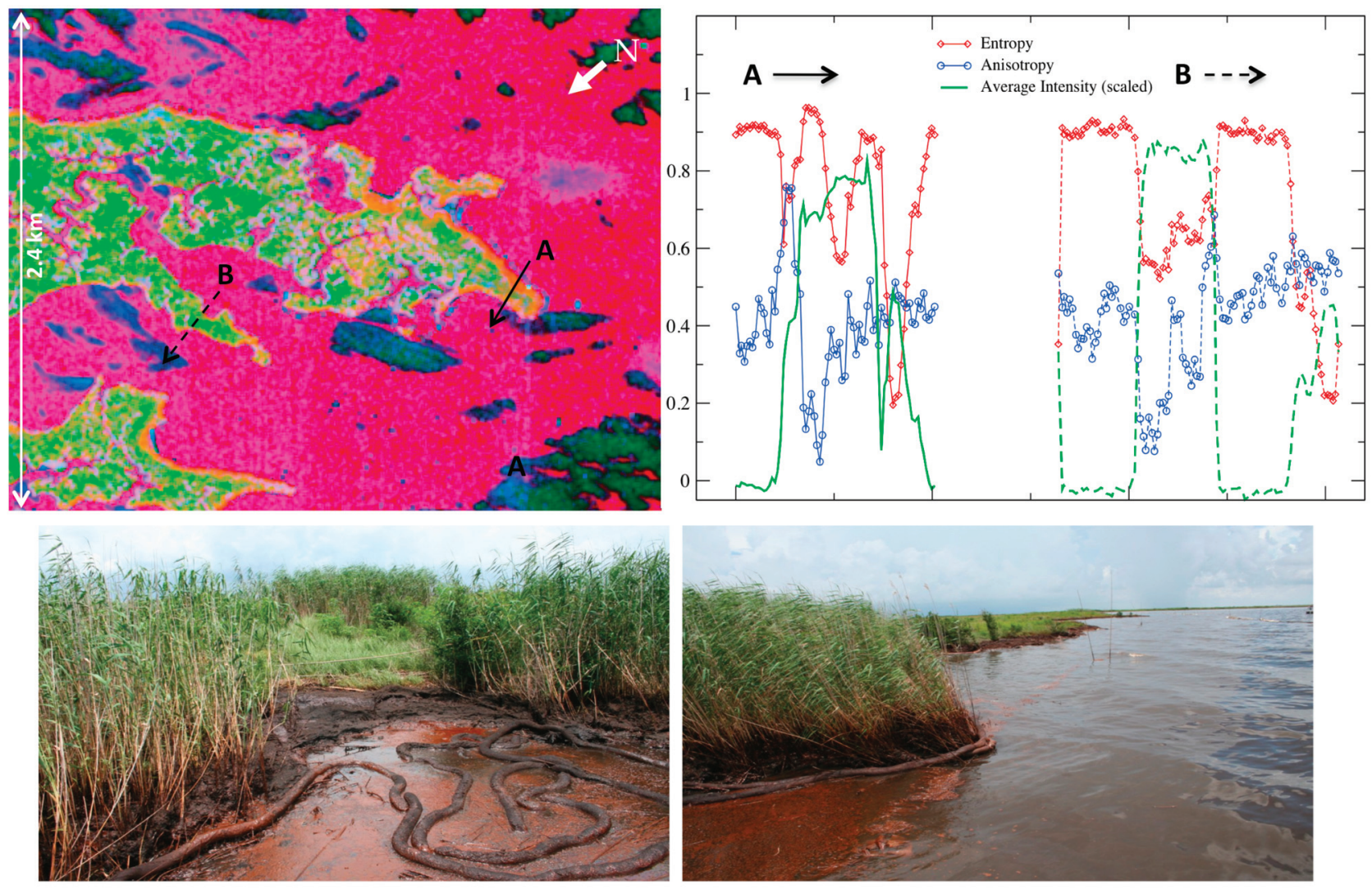

Figure 7. (top left) Image of marshland in Bay Batiste showing the Cloude-Pottier polarimetric decomposition parameters (averaged intensity, $\Lambda$, (green), entropy (red), and anisotropy (blue)). (top right) Plot of the polarimetric parameters along transects through water and land labeled A and B in top left image. (bottom) Photo of the southern shoreline of transect A (left) and view to the east from that location (right) (Photo credit, Bruce A. Davis).

the time that the photos were taken and the UAVSAR overflight, the tide was outgoing, and the water level dropped by about $0.5 \mathrm{ft}$.

We have looked at the polarimetric parameters along two transects across the land, one (A) going from the windward side to the leeward side of land that sticks out into the bay and another (B) at a more sheltered site behind the finger of land with transect $\mathrm{A}$, to see whether we can relate the polarimetric decomposition parameters seen in the bay waters to those seen in the vegetated marsh. The plots of entropy/ anisotropy/intensity along transects A and B (from south to north) in the upper right of Figure 7 show interesting differences. Along transect A, the intensity is low in the oiled water to the south of the land, increases to an intermediate level offshore from scattering from the poles in the water, then increases significantly over the land. On land, the intensity is lower along the southern third of the land and increases sharply at both north and south land/water interfaces. In the water north of the land along transect A, the intensity is low immediately offshore due to the presence of oil but increases along the edge of a large spot where there is presumed to be less surface oil. Along the same transect, the entropy is high in the water to the south, mixed due to crosspolarized scattering from the poles/booms offshore to the south, is very high on land along both north and south shorelines, and decreases in the interior land. The anisotropy change is probably indicative of different vegetation along transect A, which would alter the surface roughness.

Along transect B, there is less backscatter from any poles/ booms just offshore, so the water/land interface shows cleaner delineations. Here the intensity is higher, the entropy lower, and the anisotropy less noisy than along transect A. The difference between the shoreline and the interior land shows most clearly in the anisotropy, indicating less rough surface near the shore and possibly the presence of different vegetation in that area. Overall, the intensity and entropy results on land are consistent with oil and/or oil impact to vegetation reducing the backscatter and increasing the entropy. These results, shown here for an isolated area in Bay Batiste, are largely consistent across the entire northeastern part of 
Barataria Bay where oil had spread by late June 2010 (Ramsey et al., submitted manuscript, 2011).

An interesting observation about the results in our study region is the consistently high entropy soil surface returns (orange in image) extending along the entire southern and northern shoreline near transect A for 15-40 m inland, with the maximum inland extent of $\sim 40 \mathrm{~m}$ at the point where the bottom left photo in Figure 7 shows heavy oil surface accumulation. This consistency, combined with visual evidence of mixed shoreline canopy conditions with oiling at ground level being the common feature, indicates that UAVSAR is likely imaging below the canopy, and the radar scattering could be used to detect oil on the lower stalks and the soil. This is important because it would give a more accurate indication of the ecosystem impact of DWH oil than one would get from assessments of bare soil and vegetation canopy alone.

\subsection{Application of High-Resolution Radar to Response and Recovery}

UAVSAR was not used to support the DWH crisis response, but we have analyzed the data to identify several potential uses for high-resolution L band radar in future oil spill response activities. In addition to oil detection in coastal waters, we find that high resolution radar data can also be used to identify areas where containment booms have become beached or unattached [Jones and Davis, 2011] and areas where thick oil has accumulated on beaches. In Figure 8a, a detached boom is clearly visible offshore of an island south of Bay Jimmy; the boom condition is validated by a $0.1 \mathrm{~m}$ optical image acquired $12 \mathrm{~h}$ later. In order to assess the booms' condition, a $3 \mathrm{~m}$ resolution UAVSAR image was used in place of the standard $7 \mathrm{~m}$ resolution UAVSAR image, which did not have sufficient resolution to identify breaks in the booms or locations where they washed ashore.

In Figure 8b, we show an image of Elmer's Island, directly west of Grand Isle between Barataria and Terrebonne bays. This island received heavy oil at the end of May and was the site of a concerted cleanup effort in the Elmer's Island Wildlife Refuge at the east end of the island. Although the UAVSAR image does not show any oil in the water immediately offshore, oil that has washed up on the beach is visible in the $\Lambda$ /entropy image as the red and black area immediately inland of the water, which is green in the image.

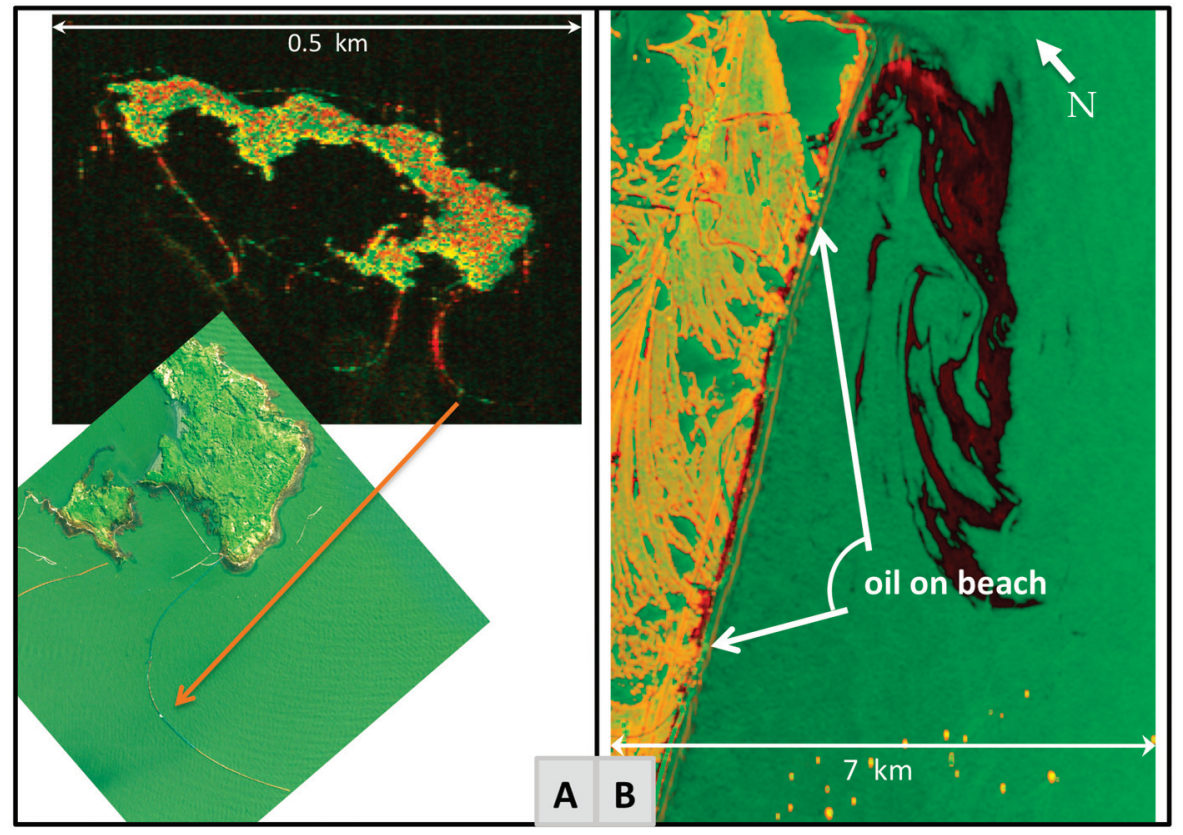

Figure 8. (a) UAVSAR $2 \mathrm{~m}$ resolution multipolarization radar image of an island in BB showing booms along the shoreline and in the surrounding water (red, HH; green, HV), along with a high-resolution optical image of part of the island taken on 24 June 2010 (Galileo Group, Inc., UCX Optical Camera, $0.1 \mathrm{~m}$ resolution). (b) Image showing the averaged intensity, $\Lambda$, (green) and entropy (red) from the Cloude-Pottier polarimetric decomposition in the vicinity of Elmer's Island, Louisiana, immediately southwest of the barrier islands shown in Figure 4e. Oil can be seen along the beaches of the island while a large oil mass approaches the shore. This image covers incidence angles of approximately $45^{\circ}$ to $55^{\circ}$. 
Oil on the beach likely becomes a prominent feature in the $\Lambda$ / entropy image because it tends to form into relatively dense clumps that scatter radar differently than the wet sands of the beach near the water.

Rapid response requires low latency product generation to be of use to first responders. During the UAVSAR flight, one of the authors (Jones) operated a prototype onboard processor system [Lou et al., 2007] to obtain a single polarization, low-resolution image of the area near the main DWH oil slick during the flight line acquisition. The technology is currently being regularly tested on UAVSAR flights, including downlinking resolution products to an internet location. This capability could shortly be available to first responders as a routine capability, enabling retargeting of the aircraft and immediate direction of responders in the future. Fully processed, high-resolution, quad-polarization results were available within a week of the 2010 deployment; this time could be significantly reduced with a concerted effort to provide lower latency products, which was not a consideration for the 2010 UAVSAR deployment.

\section{DISCUSSION OF UAVSAR DWH RESULTS}

The UAVSAR campaign to document and study the effects of the DWH oil spill on the Gulf region collected a vast amount of high-resolution (3-7 m) radar data, of which we have considered only 5 of the 30 acquired flight lines in the results presented here. Nonetheless, our survey of the data shows the unique contribution of high-resolution, fully polarimetric, L band radar in several different areas of study. We have demonstrated that the radar can be used to differentiate between several forms or states of oil in the open ocean near the DWH and within intercoastal waters using the $\mathrm{H} / \Lambda$ parameters of the Cloude-Pottier polarimetric decomposition. Within the main slick, we observe variations in the backscatter intensity correlated with different amounts and types of oil within the slick. From the analysis of oil in Barataria Bay, we attribute differences between fresh and weathered oil to the inclusion of sediment within oil in near-shore areas, improving the understanding of the scattering mechanisms associated with oil on water under different conditions. Within vegetation zones, we have shown an example of mapping the impact of oil on vegetation, including the subcanopy detection of surface oiling through polarimetric decomposition. Lastly, we have identified the locations and breaks in containment booms as well as thick accumulations of oil on beaches; both of these analyses could support high-priority activities during oil spill emergency response. Radar is unlikely to detect oil thickness with the accuracy of airborne optical assets or replace expert observers in all situations. However, radar is uniquely able to image in low-light condi- tions (arctic winter, night) and beneath cloud cover, and with its relatively large imaging swath, radar remote sensing can be used to identify areas for targeting observers more comprehensively and in a short time.

Here we have presented results of studies that are enabled by the low system noise floor of the UAVSAR radar, which allows information to be extracted from low backscatter surfaces that are largely unresolved by comparable radar systems, as well as the longer wavelength that enables penetration through a vegetated canopy to the underlying surface, in this case, found to be contaminated by oil. These show the unique contribution that UAVSAR can make to studies for which L band radar has not historically been used.

\section{APPENDIX A: H/A/ $\Lambda$ POLARIMETRIC DECOMPOSITION ANALYSIS}

The following is a simplified derivation of the eigenvectorbased polarimetric decomposition parameters used in the UAVSAR data analysis based upon the work of Cloude and Pottier [1997] and Fang and Wen [2005].

Fully polarimetric radar backscatter cross-section data for each pixel in an image can be arranged into the Hermitian covariance matrix,

$$
C=\left[\begin{array}{ccc}
S_{\mathrm{HH}} S_{\mathrm{HH}}^{*} & \sqrt{2} S_{\mathrm{HH}} S_{\mathrm{HV}}^{*} & S_{\mathrm{HH}} S_{\mathrm{VV}}^{*} \\
\sqrt{2} S_{\mathrm{HV}} S_{\mathrm{HH}}^{*} & 2 S_{\mathrm{HV}} S_{\mathrm{HV}}^{*} & \sqrt{2} S_{\mathrm{HV}} S_{\mathrm{VV}}^{*} \\
S_{\mathrm{VV}} S_{\mathrm{HH}}^{*} & \sqrt{2} S_{\mathrm{VV}} S_{\mathrm{HV}}^{*} & S_{\mathrm{VV}} S_{\mathrm{VV}}^{*}
\end{array}\right],
$$

where $S_{\mathrm{TR}}$ is the complex backscatter coefficient for the transmit $(\mathrm{T})$ and receive $(\mathrm{R})$ polarization. Because $\mathbf{C}$ is a Hermitian matrix, it always has three real, nonnegative eigenvalues. These eigenvalues are equivalent to the eigenvalues of the coherency matrix, which is the base matrix for the $\mathrm{H} / \mathrm{A} / \alpha$ method, because of the linear relationship between the two matrices [Cloude and Pottier, 1996, 1997; Lee and Pottier, 2009]. To allow for a stochastic analysis of distributed scatterers [Cloude and Pottier, 1997] and to remove biasing [Lee et al., 2008; Lopez-Martinez et al., 2005], C should be averaged over a spatial window.

The covariance matrix $\mathbf{C}$ can be parameterized using eigenvector decomposition. One such parameter, the averaged intensity, $\Lambda$, is the weighted mean of the eigenvalues of $\mathbf{C}$, given as

$$
\Lambda=\sum_{i=1}^{3} \lambda_{i} p_{i},
$$

where $p_{i}$, the pseudo-probability, is defined as

$$
p_{i}=\frac{\lambda_{i}}{\lambda_{1}+\lambda_{2}+\lambda_{3}} .
$$


Using the pseudo-probabilities, the randomness of the distributed scatterers within the averaging window can be evaluated from the entropy [Cloude and Pottier, 1996, 1997],

$$
H=-\sum_{i=1}^{3} p_{i \log _{3}} p_{i} \quad 0 \leq H \leq 1 .
$$

Low entropy values $(H<0.3)$ indicate a single dominant scatterer or one high probability and one medium probability scatterer. High entropy values $(>0.7)$ indicate random scattering or three nearly equivalent eigenvalues. Finally, the anisotropy, which is the measure of the departure from azimuthal symmetry, is defined as

$$
A=\frac{\lambda_{2}-\lambda_{3}}{\lambda_{2}+\lambda_{3}} \quad 0 \leq A \leq 1 .
$$

For backscatter from the ocean surface, the covariance matrix has a dominant eigenvalue with near-unity pseudoprobability. Therefore, because the sum of the eigenvalues is equal the trace of the matrix, equation (A2) can be rewritten for scattering from clean water as

$$
\Lambda_{\text {Bragg }} \approx \operatorname{trace}(C) .
$$

While the averaged intensity for ocean Bragg scattering approaches the trace of $C$, the entropy goes to zero in the limit of unity pseudo-probability, and the anisotropy remains nonzero as a measure of the small-scale surface roughness.

Acknowledgments. We thank the UAVSAR team at the Jet Propulsion Laboratory and Dryden Flight Research Center for the excellent support in planning and conducting the UAVSAR mission and processing the data. We thank Dr. Bruce A. Davis of the Department of Homeland Security for acquiring the ground survey data within Barataria Bay concurrent with the UAVSAR flight and Dr. Zhihong Pan of the Galileo Group, Inc., for donation of their hyperspectral and optical images collected over Bay Jimmy. We also acknowledge Dr. Hans Graber and Dr. Michael Caruso from the University of Miami for advice regarding the ERS-2 SAR collection during the DWH spill. The UAVSAR data are courtesy of NASA/JPL-Caltech (http:// uavsar.jpl.nasa.gov or http://www.asf.alaska.edu). The ERS-2 SAR imagery is provided by the European Space Agency. The research described in this paper was carried out in part at the Jet Propulsion Laboratory, California Institute of Technology, under a contract with the National Aeronautics and Space Administration.

\section{REFERENCES}

Alpers, W., and H. Hühnerfuss (1988), Radar signatures of oil films floating on the sea surface and the Marangoni Effect, J. Geophys. Res., 93(C4), 3642-3648, doi:10.1029/JC093iC04p03642.

Brekke, C., and A. H. S. Solberg (2005), Oil spill detection by satellite remote sensing, Remote Sens. Environ., 95(18), 1-13, doi:10.1016/j.rse.2004.11.015.
Cloude, S., and E. Pottier (1996), A review of target decomposition theorems in radar polarimetry, IEEE Trans. Geosci. Remote Sens., 34(2), 498-518, doi:10.1109/36.485127.

Cloude, S., and E. Pottier (1997), An entropy based classification scheme for land applications of polarimetric SAR, IEEE Trans. Geosci. Remote Sens., 35(1), 68-78, doi:10.1109/36.551935.

Creamer, D. B., and J. A. Wright (1992), Surface films and wind wave growth, J. Geophys. Res., 97(C4), 5221-5229, doi:10.1029/ 91JC01876.

Donelan, M. A., and W. J. Pierson Jr. (1987), Radar scattering and equilibrium ranges in wind-generated waves with application to scatterometry, J. Geophys. Res., 92(C5), 4971-5029, doi:10.1029/ JC092iC05p04971.

Espedal, H. A., and T. Wahl (1999), Satellite SAR oil spill detection using wind history information, Int. J. Remote Sens., 20(1), 4965, doi:10.1080/014311699213596.

Espedal, H. A., O. M. Johannessen, J. A. Johannessen, E. Dano, D. R. Lyzenga, and J. C. Knulst (1998), COASTWATCH'95: ERS 1/2 SAR detection of natural film on the ocean surface, J. Geophys. Res., 103(C11), 24,969-24,982, doi:10.1029/98JC01660.

Fang, C., and H. Wen (2005), A new classification method based on Cloude-Pottier eigenvalue/eigenvector decomposition, in Geoscience and Remote Sensing Symposium, IGARSS 2005, pp. 296-299, Inst. of Electr. and Electron. Eng., Piscataway, N. J., doi:10.1109/IGARSS.2005.1526166.

Fingas, M. F., and C. E. Brown (1997), Review of oil spill remote sensing, Spill Sci. Tech. Bull., 4, 199-208.

Gade, M., W. Alpers, H. Hühnerfuss, V. R. Wismann, and P. A. Lange (1998a), On the reduction of the radar backscatter by oceanic surface films: Scatterometer measurements and their theoretical interpretation, Remote Sens. Environ., 66(1), 52-70, doi:10.1016/S0034-4257(98)00034-0.

Gade, M., W. Alpers, H. Hühnerfuss, H. Masuko, and T. Kobayashi (1998b), Imaging of biogenic and anthropogenic ocean surface films by the multifrequency/multipolarization SIRC/X-SAR, J. Geophys. Res., 103(C9), 18,851-18,866, doi:10.1029/ 97JC01915.

Harvey, E. H. (1925), The surface tension of crude oils, Ind. Eng. Chem., 17(1), 85, doi:10.1021/ie50181a042.

Hensley, S., et al. (2008), The UAVSAR Instrument: First Description and Results, paper presented at 2008 IEEE Radar Conference, Inst. of Electr. and Electron. Eng., Rome, Italy, doi:10.1109/RADAR.2008.4720722.

Hensley, S., H. Zebker, C. Jones, T. Michel, R. Muellerschoen, and B. Chapman (2009), First deformation results using the NASA/ JPL UAVSAR instrument, in Proceedings of the 2nd AsianPacific Conference on Synthetic Aperture Radar, pp. 10511055, Inst. of Electr. and Electron. Eng., Piscataway, N. J., doi:10.1109/APSAR.2009.5374246.

Jones, C. E., and B. A. Davis (2011), High resolution radar for response and recovery: Monitoring containment booms in Barataria Bay, Photogramm. Eng. Remote Sens., 77(2), 102-105.

Lee, J. S., and E. Pottier (2009), Polarimetric Radar Imaging: From Basics to Applications, CRC Press, Boca Raton, Fla. 
Lee, J. S., T. Ainsworth, J. Kelley, and C. Lopez-Martinez (2008), Evaluation and bias removal of multilook effect on entropy/ alpha/anisotropy in polarimetric SAR decomposition, IEEE Trans. Geosci. Remote Sens., 46(10), 3039-3052, doi:10.1109/ TGRS.2008.922033.

Leibovich, S. (1983), The form and dynamics of Langmuir circulations, Annu. Rev. Fluid Mech., 15, 391-427, doi:10.1146/annurev.fl.15.010183.002135.

Lin, V., B. Strovers, J. Lee, and R. Beck (2008), Platform Precision Autopilot overview and flight test results, paper presented at 2008 AIAA Guidance, Navigation, and Control Conference, Honolulu, Hawaii.

Liu, Y., R. H. Weisberg, C. Hu, C. Kovach, and R. Riethmüller (2011), Evolution of the Loop Current system during the Deepwater Horizon oil spill event as observed with drifters and satellites, in Monitoring and Modeling the Deepwater Horizon Oil Spill: A Record-Breaking Enterprise, Geophys. Monogr. Ser., doi:10.1029/2011GM001127, this volume.

Lopez-Martinez, C., E. Pottier, and S. Cloude (2005), Statistical assessment of eigenvector-based target decomposition theorems in radar polarimetry, IEEE Trans. Geosci. Remote Sens., 43(9), 2058-2074, doi:10.1109/TGRS.2005.853934.

Lou, Y., S. Chien, R. Muellerschoen, and S. Saatchi (2007), Autonomous disturbance detection and monitoring system with UAVSAR, paper presented at the 6th Annual NASA Earth Science Technology Conference (ESTC2007), NASA, Adelphi, Md.

Marmorino, G. O., G. B. Smith, J. V. Toporkov, M. A. Sletten, D. Perkovic, and S. J. Frasier (2008), Evolution of ocean slicks under a rising wind, J. Geophys. Res., 113, C04030, doi:10.1029/ 2007JC004538.

National Research Council (U.S.) Committee on Oil in the Sea: Inputs, Fates, and Effects (2003), Oil in the Sea III: Inputs, Fates, and Effects, Natl. Acad. Press, Washington, D. C.

Phillips, O. M. (1957), On the generation of waves by turbulent wind, J. Fluid Mech., 2(5), 417-445, doi:10.1017/ S0022112057000233.

Valenzuela, G. (1978), Theories for the interaction of electromagnetic and oceanic waves-A review, Boundary Layer Meteorol., 13, 61-85, doi:10.1007/BF00913863.

Wahl, T., et al. (1996), Radar satellites: A new tool for pollution monitoring in coastal waters, Coastal Manage, 24(1), 61-71, doi:10.1080/08920759609362281.

Wismann, V., M. Gade, W. Alpers, and H. Hühnerfuss (1998), Radar signatures of marine mineral spills measured by an airborne multi-frequency radar, Int. J. Remote Sens., 19(18), 36073623, doi:10.1080/014311698213849.

Wright, J. (1968), A new model for sea clutter, IEEE Trans. Antennas Propag., 16(2), 217-223, doi:10.1109/TAP.1968.1139147.

S. Hensley, B. Holt, and C. E. Jones, Jet Propulsion Laboratory, California Institute of Technology, 1200 East California Boulevard, Pasadena, CA 91125, USA. (cathleen.jones@jpl.nasa.gov)

B. Minchew, Seismological Laboratory, California Institute of Technology, 1200 East California Boulevard, Pasadena, CA 91125, USA. 